\title{
A Step-Up Modular High-Voltage Pulse Generator Based on Isolated Input-Parallel/Output-Series Voltage-Boosting Modules and Modular Multilevel Sub-modules
}

\author{
Ahmed Darwish, Mohamed A. Elgenedy, Student Member, IEEE, Stephen J. Finney, \\ Barry W. Williams, and Jim R. McDonald
}

\begin{abstract}
Irreversible electroporation for disinfection applications involve exposing the specimen cellmembrane to a pulsed electric field in order to kill harmful microorganisms. High voltage (HV) pulses, of relatively short durations in range of few micro-seconds, are generated across the sample chamber. The HV pulse specifications such as: voltage magnitude, waveform, repetition rate, and duration differ according to the conditions of the sample being processed. This paper proposes a new step-up power electronic converter topology for generating the required HV pulses from a relatively low input voltage. The converter consists of two main stages; the first stage is responsible for boosting the input voltage to the desired level using inputparallel/output-series connected dc/dc modules while the second stage forms the required HV pulses with the proper magnitude, duration and repetition rate using modular multilevel converter sub-modules. The proposed topology is able to produce the HV pulses with controlled voltage and current stresses across the employed semiconductor switches and diodes, hence, it can be implemented with the market-available semiconductor technology. Mathematical analysis of the proposed topology is developed and MATLAB/Simulink simulation results explore operational conditions. Experimental results from a scaled-down prototype validate the functionality of the proposed system.
\end{abstract}

Index Terms-DC/DC converters, Irreversible electroporation, Modular multilevel converters, pulsed electric field, pulse waveforms generator, voltage boosting

\section{INTRODUCTION}

In the irreversible electroporation (IRE) process, a harmful microorganism cell-membrane is subjected to high electric field strength via a train of sufficiently high-voltage (HV) pulses [1]. IRE is useful in tumor treatment, food sterilization and air infection control [2].

Manuscript received March 12, 2017; revised May 24, 2017; accepted October 13, 2017. This work was supported by the Engineering and Physical Sciences Research Council (EPSRC) under grant EP/K035096/1.

A. Darwish and B. Williams are with the Electronic and Electrical Engineering Department, University of Strathclyde, Glasgow, UK.

M. A. Elgenedy is with the Department of Electronic and Electrical Engineering, University of Strathclyde, Glasgow, UK, and also with the Electrical Engineering Department, Faculty of Engineering, Alexandria University, Alexandria, Egypt.

$\mathrm{J}$. McDonald is Principal and Vice Chancellor of the University of Strathclyde, Glasgow, UK.

S. Finney is with Electronics and Electrical Engineering, Edinburgh University, Edinburgh, UK.
It is a good candidate for chlorination in water disinfection applications [3]. For a successful IRE process, the strength of the applied electric field, typically ranges between $2.5 \mathrm{kV} / \mathrm{cm}$ to $12 \mathrm{kV} / \mathrm{cm}$, according to the type of the harmful microorganism and the application [4]. Applying HV pulses in $\mathrm{kV}$ range and microsecond range should deactivate the harmful microorganisms in the water under treatment [5]. Therefore,

HV pulse generators (PGs) are the pillar of IRE application, and should meet several challenging aspects such as modularity, scalability and flexibility [6]. Power electronics based PGs superseded classical PGs such as Blumlein lines, pulse forming networks and Marx generator aiming to meet these aspects [7].

The existing modularity with modular multilevel converter (MMC) sub-modules (SMs) has been harnessed to generate HV pulses for IRE [8]-[14]. Not only conventional rectangular pulse-waveforms can be generated by MMC based PGs, but a wide range of pulse-waveforms is also possible [5] and [10]. The majority of these topologies require an HVDC input supply and the obtained pulse peak-voltage is that of the input HVDC level. They require balancing of the individual SM capacitor voltages, ramping the HVDC input at start-up/shutdown, and protection against HVDC side faults. An exception for obtaining stepped-up voltage pulse from low voltage (LV) DC input are [13] and [14], where several series connected MMC SM capacitors are charged sequentially, then connected in series across the load to discharge. However, the voltage step-up and the pulse repetition frequency are dependent on the number of SMs and the charging process is achieved via resistors in [13] and via resistive-inductive branch in [14].

Solid-state Marx generators are introduced in the literature to provide flexibility compared with the classical Marx generator [15]. However, the ratings of the utilized switches are not identical in order to cope with their respective voltage stresses [13]. In [16], several stages of capacitor-diode voltage multipliers are incorporated to generate $\mathrm{HV}$ pulses from a LVDC input, but a HV switch is required to chop the pulse across the load, hence, series connection of switches is not avoided. In [17], an isolated forward converter with a step-up transformer is proposed, however, extending the topology to more than $5 \mathrm{kV}$ requires series-connected semiconductors. Also, the core reset of the transformers is problematic and increasing the number of transformers increases the leakage inductance which limits the generated pulse-duration. In [18] 
two boost converters charge two capacitors from a relatively LVDC input. The load is connected differentially between the two capacitors, hence, HV bipolar pulses are obtained from a LVDC input. But the passive parameters of the converters affect the flexibility of the generator and two HV switches are required, hence, series-connected switches is inevitable.

In this paper, a unipolar step-up PG (SUPG) fed from a LVDC supply is proposed based on isolated inputparallel/output-series (IPOS) voltage-boosting modules (VBMs) and MMC-SMs. The VBMs are isolated via nanocrystalline core based transformers which have low leakage and magnetizing inductance and are suitable for highfrequency operation [19]-[20]. The high voltage step-up is obtained from three mechanisms: the number of utilized VBMs, the voltage conversion ratio of the individual VBM, and the turns ratios of the step-up isolation transformers. The generated HVDC from connecting the output of the individual VBMs in series is chopped by employing two arms of series connected MMC-SMs across the load, hence, the SMcapacitors actively clamp the voltage across the semiconductor switches [21]. High repetition pulse rates are possible, independent of the employed number of VBMs or MMC-SMs. Mathematical modeling of the proposed PG is introduced while the methodology of selecting parameters is detailed. SUPG performance is assessed via Matlab/Simulink simulations and scaled-down experimentation.

\section{Basic Voltage Boosting Module of The SUPG}

The basic VBM of the proposed SUPG is shown in Fig. 1. Unlike conventional DC-DC converters [22], the secondary side switches $S_{x 1}$ and $S_{x 2}$ are not necessarily working in a complementary manner. The switching pattern for the VBM devices and the developed circuit configurations are illustrated in Fig. 2. The VBM operation can be explained as follows,

$$
\text { i) } \quad t_{1}\left(0<t<\frac{D-\delta}{2} t_{s}\right)
$$

During period $t_{1}$, (Fig. 2b) the input current $I_{\text {in }}$ increases and $L_{\text {in }}$ charges, the load is connected to an open circuit, and the voltage of capacitors $C_{c 1}$ and $C_{c 2}$ are constant. The differential equations that describe the circuit in this period can be expressed as

$$
\begin{gathered}
\frac{d I_{i n}}{d t}=\frac{1}{L_{i n}} V_{i n} \\
\frac{d V_{c 1}}{d t}=0 \\
\frac{d V_{c 2}}{d t}=0 \\
I_{o}=0
\end{gathered}
$$

ii)

$$
t_{2}\left(\frac{D-\delta}{2} t_{s}<t<\frac{D+\delta}{2} t_{s}\right)
$$

During $t_{2}$, (Fig. 2c) the input current $I_{\text {in }}$ continues to increase while the load is connected to capacitor $C_{\mathrm{c} 2}$ in series with $S_{x 1}$. This leads to a sudden voltage pulse across the load. Capacitors $C_{c 1}$ and $C_{c 2}$ discharge and their voltages decrease.
The differential equations that describe the circuit in this period are:

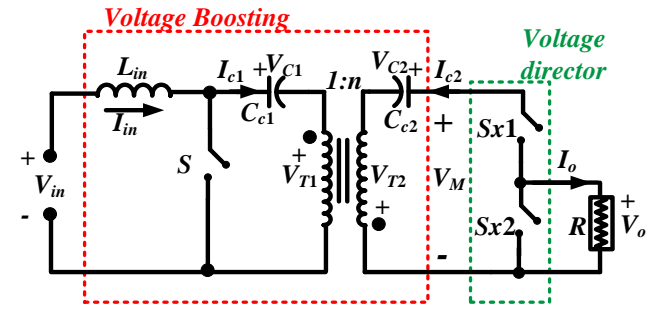

Fig. 1. The basic VBM

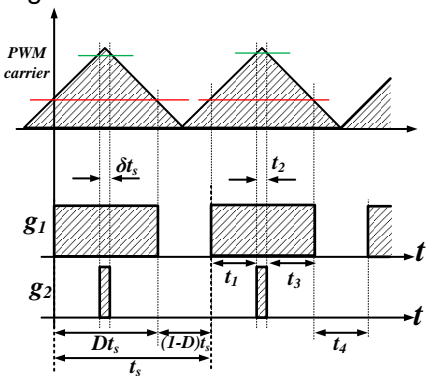

(a)

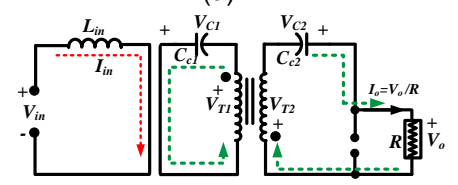

(c) $\left(S O N-S_{x 1}\right.$ ON and $S_{x 2}$ OFF)

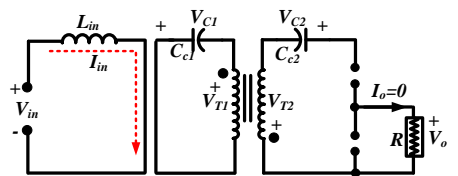

(b) (SON $-S_{x 1}$ and $S_{x 2}$ OFF)

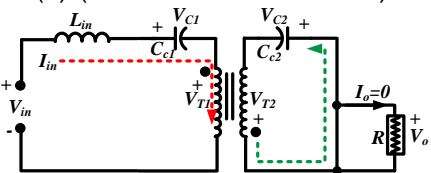

(d) (S OFF - $S_{x 1}$ and $S_{x 2}$ ON)
Fig. 2. Normal VBM operation: (a) operational states, (b) circuit configurations during $t_{1}$ and $t_{3}$, (c) $t_{2}$ and (d) $t_{4}$

$$
\begin{aligned}
& \frac{d I_{i n}}{d t}=\frac{1}{L_{i n}} V_{i n} \\
& \frac{d V_{c 1}}{d t}=\frac{-n}{C_{c 1}} I_{o} \\
& \frac{d V_{c 2}}{d t}=\frac{-1}{C_{c 2}} I_{o} \\
& I_{o}=\frac{n V_{c 1}+V_{c 2}}{R}
\end{aligned}
$$

iii) $\quad t_{3}\left(\frac{D+\delta}{2} t_{s}<t<D t_{s}\right)$

The same operation is repeated as in period $t_{1}$.

$$
\text { iv) } t_{4}\left(D t_{s}<t<t_{s}\right)
$$

$I_{\text {in }}$ decreases and $L_{\text {in }}$ discharges into the capacitors while the voltages $V_{c 1}$ and $V_{c 2}$ increase. No voltage is impressed across the load $R$, see Fig. 2d. The differential equations that describe the circuit in this period are

$$
\begin{gathered}
\frac{d I_{i n}}{d t}=\frac{1}{L_{i n}} V_{i n}-\frac{1}{L_{i n}} V_{c 1}-\frac{1}{n L_{i n}} V_{c 2} \\
\frac{d V_{c 1}}{d t}=\frac{1}{C_{c 1}} I_{i n} \\
\frac{d V_{c 2}}{d t}=\frac{1}{n C_{c 2}} I_{i n} \\
I_{o}=0
\end{gathered}
$$




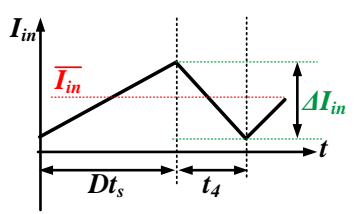

(a)

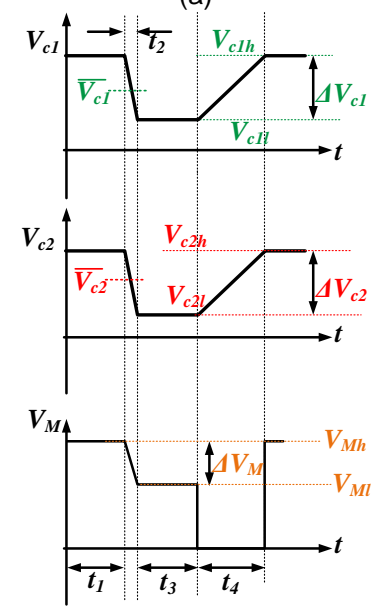

(c)

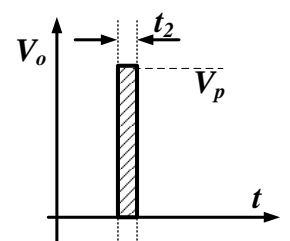

(e)

Fig. 3. Waveforms of basic VBM: (a) current through the input inductor, (b) current through $\mathrm{C}_{c 1}$ and $\mathrm{C}_{c 2}$, (c) voltage across $\mathrm{C}_{c 1}$ and $\mathrm{C}_{c 2}$, (d) isolation transformer primary and secondary voltages and (e) the output generated pulse.

The voltage and current waveforms of the basic VBM during one complete cycle of pulse generation are depicted in Fig. 3. Fig. 3a shows the current through the input inductor. The current through $C_{c 1}$ and $C_{c 2}$ are shown in Fig. 3b, while the voltage waveforms across $C_{c 1}$ and $C_{c 2}$ are shown in Fig. $3 \mathrm{c}$ along with the resultant VBM terminal voltage $V_{M}$. The isolation transformer's primary and secondary voltages are shown in Fig. 3d. Finally, the generated voltage pulse is shown in Fig. 3e.

Assuming the pulse duty ratio $\delta$ is small with respect to the main duty ratio $D$ and solving equations (1) to (3), the values of the circuit currents and voltages are

$$
\begin{gathered}
\bar{I}_{i n}=\frac{\delta V_{p}^{2}}{R V_{i n}} \\
\Delta I_{i n}=\frac{D V_{i n} t_{s}}{L_{i n}}
\end{gathered}
$$

$$
\begin{gathered}
I_{c 1 h}=\frac{\delta V_{p}^{2}}{R V_{i n}}+\frac{D V_{i n} t_{s}}{2 L_{i n}} \\
I_{c 1 l}=\frac{\delta V_{p}^{2}}{R V_{i n}}-\frac{D V_{i n} t_{s}}{2 L_{i n}} \\
V_{P}=\frac{n}{1-D} V_{i n} \\
\bar{V}_{c 1}=V_{i n} \\
\Delta V_{c 1}=\frac{(1-D) \bar{I}_{i n} t_{s}}{C} \\
V_{c 1 h}=V_{i n}+\frac{(1-D) \bar{I}_{i n} t_{s}}{2 C_{c 1}} \\
\overline{V_{c 2}}=\frac{n D}{1-D} V_{i n} \\
\Delta V_{c 2}=\frac{(1-D) \bar{I}_{i n} t_{s}}{n C_{c 2}} \\
V_{c 2 h}=\frac{n D}{1-D} V_{i n}+\frac{(1-D) \bar{I}_{i n} t_{s}}{2 n C_{c 2}} \\
V_{c 2 l}=\frac{n D}{1-D} V_{i n}-\frac{(1-D) \bar{I}_{i n} t_{s}}{2 n C_{c 2}} \\
V_{M l}=V_{c 2 h}+n V_{c 1 h}+n V_{c 1 l} \\
V_{c 2 l}
\end{gathered}
$$

III.StRuCtURE AND OPERATION OF THE PROPOSED SUPG TOPOLOGY

Fig. 4 shows the proposed SUPG is comprised of the PISO of $N$ of the voltage boosting modules shown in Fig. 1. Galvanic isolation of the boosting part in the individual VBM enables series connection of $N$ modules, while for $\mathrm{HV}$ voltage sharing the initial switches $S_{x 1}$ and $S_{x 2}$ are replaced by two arms (Arm1 and Arm2) of series connected MMC-SMs.

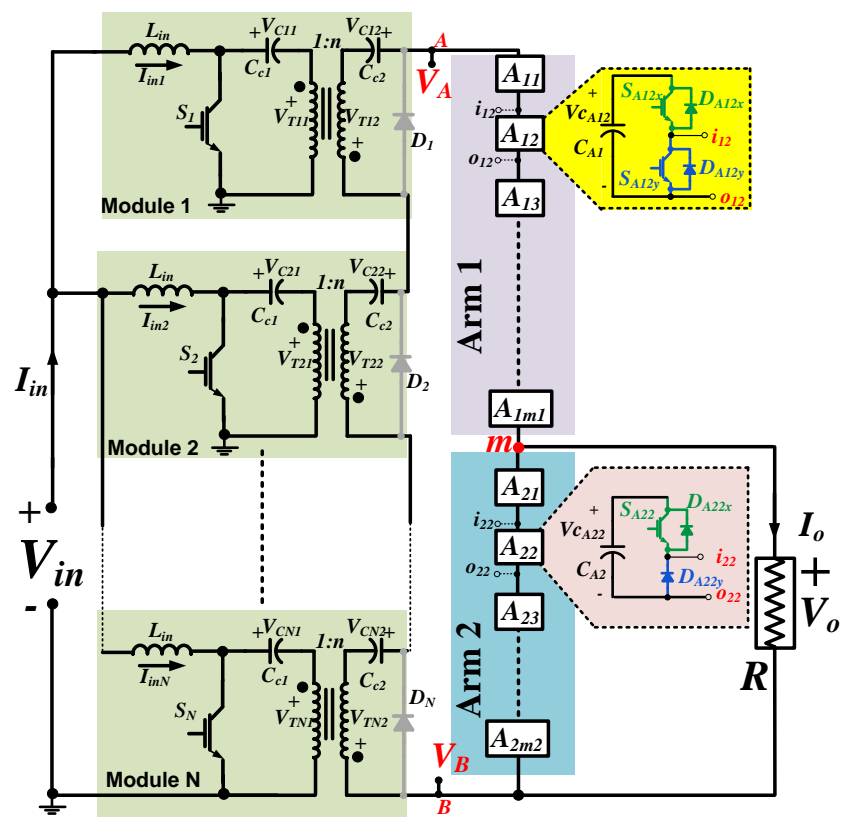

Fig. 4. The proposed SUPG. 
Arm1 is formed of $m_{1}$ conventional half-bridge SMs, while each of the $m_{2}$ SMs of Arm2 are formed with two diodes, a switch, and a capacitor.

The basic operation of the proposed SUPG can be described as follows: with the operation sequence shown in Fig. 2a, switches $S_{1}, S_{2} \ldots S_{\mathrm{N}}$ are turned ON during $t_{1}, t_{2}$, and $t_{3}$ and OFF otherwise, allowing the input inductors to energise. During $t_{2}$, the lower switches of the SMs in Arm1 ( $\mathrm{S}_{\mathrm{A} 1 \mathrm{jy}}$ where, $j \in$ $\left.\left\{1,2, \ldots m_{1}\right\}\right)$ are turned $\mathrm{ON}$, that is bypassed while the lower diodes in Arm2 ( $\mathrm{D}_{\mathrm{A} 2 \mathrm{ky}}$ where $\left.k \in\left\{1,2, \ldots m_{2}\right\}\right)$ are reverse biased, thus, a voltage difference $V_{A B}$ is impressed across the load. During $t_{4}$, the lower diodes of the SMs in Arm1 ( $\mathrm{D}_{\mathrm{A} 1 \mathrm{jy}}$ where $j \in\left\{1,2, \ldots m_{1}\right\}$ ) and Arm2 conduct a charging current of $I_{i n} / n / N$ through the $N$ charging capacitors $C_{c 2}$.

Diodes $\left(D_{1}, D 2, \ldots D_{N}\right)$ are installed to prevent unintended series connection of secondary sides of the isolation transformers due to any delay in primary side switches gate signals.

Thus based on the VBM in section II and assuming that the component values of the $N$ VBMs are identical, the average voltages of the voltage boosting stage can be calculated as

$$
\begin{gathered}
\bar{V}_{C i 1}=V_{i n} \\
\bar{V}_{C i 2}=\frac{n D}{1-D} V_{i n}
\end{gathered}
$$

where $i \in\{1,2, \ldots N\}$. The input inductor current of the individual VBMs are:

$$
\bar{I}_{i n i}=\frac{\delta V_{p}^{2}}{N R V_{i n}}
$$

The primary and secondary transformer voltages are:

$$
\begin{gathered}
{\overline{V_{T i 1}}}= \begin{cases}-V_{\text {in }} & 0<t<D t_{s} \\
\frac{D V_{i n}}{(1-D)} & D t_{s}<t<t_{s}\end{cases} \\
\overline{V_{T i 2}}= \begin{cases}-n V_{i n} & 0<t<D t_{s} \\
\frac{n D V_{i n}}{(1-D)} & D t_{s}<t<t_{s}\end{cases}
\end{gathered}
$$

During $t_{2}$, the midpoint ' $m$ ' is connected to the upper point ' $A$ ' through the semiconductor switches $S_{\mathrm{Aljy}}$. Consequently, a voltage pulse with duty ratio $\delta$ and magnitude $V_{p}$ is impressed across the output load $R$. The voltage peak is:

$$
\begin{aligned}
V_{p} & =\sum_{i=1}^{i=N}\left(V_{C i 2}-V_{T i 2}\right) \\
& =N\left(\frac{n D}{1-D} V_{i n}+n V_{i n}\right) \\
& =\frac{n N}{1-D} V_{i n}
\end{aligned}
$$

As concluded from (8), the output voltage is amplified by three mechanisms: (i) the $N$ utilized VBMs basic cell converters, (ii) transformer turns ratio $n$, and (iii) the individual VBMs duty ratio $D$. The average capacitor voltages of the Arm1 and Arm2 SM-capacitors are:

$$
\begin{gathered}
V_{c A 1 j}=\frac{V_{p}}{m_{1}}, \quad j \in\left\{1,2, . . m_{1}\right\} \\
V_{c A 2 k}=\frac{V_{p}}{m_{2}}, \quad k \in\left\{1,2, . . m_{2}\right\}
\end{gathered}
$$

In the next section, a design process is presented for SUPG system parameter selection.

\section{Proposed Supg parameters Selection}

The main merits of the proposed SUPG are that of obtaining high voltage output pulses with the readily available semiconductor technology and a relatively low input voltage; thus modularity, scalability and flexibility features arise. Starting from the load side, the voltage and current stresses of the Arm1 SMs are:

$$
\begin{gathered}
\hat{V}_{S A 1 j x}=\frac{V_{p}}{m_{1}}, \quad j \in\left\{1,2, . . m_{1}\right\} \\
\hat{V}_{S A 1 j y}=\frac{V_{p}}{m_{1}} \\
\hat{I}_{S A 1 j y}=\frac{V_{p}}{R} \\
\hat{I}_{D A 1 j y}=\frac{\bar{I}_{i n}}{n}
\end{gathered}
$$

The current stresses of the clamping switches and diodes $\left(S_{A l j x}\right.$ and $\left.D_{A l j x}\right)$ are relatively small and hence, switches with lower current ratings can be used. Similarly, the voltage and current stresses of the Arm2 SMs are:

$$
\begin{gathered}
\hat{V}_{S A 2 k x}=\frac{V_{p}}{m_{1}}, \quad k \in\left\{1,2, . . m_{2}\right\} \\
\hat{V}_{D A 2 k y}=\frac{V p}{m_{1}} \\
\hat{I}_{D A 2 k y}=\frac{\bar{I}_{i n}}{n}
\end{gathered}
$$

Assuming a modular design and ' $\gamma$ ' and ' $\varepsilon$ ' are the voltages and current derating factors of the Arm SMs devices, the number of Arm1 SMs $\left(m_{l}\right)$ is:

$$
\begin{gathered}
m_{1} \geq \frac{V_{p}}{\gamma V_{r A l}} \\
I_{r A 1} \geq \frac{\bar{I}_{\text {in_max }}}{\varepsilon n}
\end{gathered}
$$

where, $V_{r A l}$ and $I_{r A l}$ are the rated voltage and current of Arm1 devices respectively. The number of Arm2 SMs $\left(m_{2}\right)$ is:

$$
m_{2} \geq \frac{V_{p}}{\gamma V_{r A 2}}
$$

where, $V_{r A 2}$ is the rated voltage of Arm 2 devices. As they conduct the charging currents of the clamping capacitors, the current ratings of Arm2 SM devices can be small compared to Arm1 device ratings. Similarly, assume that ' $\alpha$ ' and ' $\beta$ ' are the voltages and current derating factors of the devices in the 
VBMs, the number of the boosting modules $(N)$ is:

$$
N \geq \frac{\bar{I}_{\text {in_max }}}{\beta I_{r M}}
$$

The maximum duty ratio $D_{\max }$ is related to the voltage stresses across the module's devices,viz.:

$$
D_{\max } \leq \frac{V_{r M}-\alpha V_{i n}}{V_{r M}}
$$

' $V_{r M}$ ' and ' $I_{r M}$ 'are the rated voltage and current of the VBM devices.

The passive element values are selected in order to keep the ripple current and voltage within certain ranges. The ripples across the different elements can be calculated from [23], [24] as:

$$
\begin{gathered}
\Delta V_{c c 1}=\frac{\bar{I}_{i n \__{-} \max }\left(1-D_{\max }\right) t_{s}}{N C_{C 1}} \\
\Delta V_{c c 2}=\frac{\bar{I}_{i n \__{-} \max }\left(1-D_{\max }\right) t_{s}}{n N C_{C 2}} \\
\Delta I_{i n 1}=\frac{V_{i n} D_{\max } t_{s}}{L_{i n}}
\end{gathered}
$$

Defining the ripple factors as:

$$
x=\Delta V_{C c 1} / \bar{V}_{c c 1}, y=\Delta V_{C c 2} / \bar{V}_{C c 2} \text {, and } z=\Delta I_{i n 1} / \bar{I}_{i n 1}
$$

Accordingly, the passive element values should be kept as:

$$
\begin{gathered}
C_{C 1} \geq \frac{\bar{I}_{\text {in_max }}\left(1-D_{\max }\right)^{2} t_{s}}{N x V_{\text {in }}} \\
C_{C 2} \geq \frac{\bar{I}_{\text {in_max }}\left(1-D_{\max }\right)^{2} t_{s}}{n^{2} N y V_{\text {in }}} \\
L_{\text {in }} \geq \frac{N V_{\text {in }} D_{\text {max }} t_{s}}{z \bar{I}_{\text {in_max }}}
\end{gathered}
$$

\begin{tabular}{|c|c|}
\hline Parameter & Value \\
\hline Input de voltage & $V_{\text {in }}=100 \mathrm{~V}$ \\
\hline Output Pulse peak-voltage & $V_{p}=10 \mathrm{kV}$ \\
\hline Pulse repetition time & $t_{s}=100 \mu \mathrm{s}$ \\
\hline Maximum pulse duty ratio & $\delta_{\max }=0.1$ \\
\hline Maximum input current & $I_{\text {in_max }}=200 \mathrm{~A}$ \\
\hline Rated voltages of SM devices & $V_{r A 1}=V_{r A 2}=1500 \mathrm{~V}$ \\
\hline Rated currents of SM devices & $I_{r A l}=I_{r A 2}=40 \mathrm{~A}$ \\
\hline Rated voltage of VBM devices & $V_{r M}=600 \mathrm{~V}$ \\
\hline Rated current of VBM devices & $I_{r M}=60 \mathrm{~A}$ \\
\hline Derating factors of VBMs & $\alpha=0.75$ and $\beta=0.75$ \\
\hline Derating factors of MMC-SMs & $\gamma=0.75$ and $\varepsilon=0.75$ \\
\hline Number of VBMs & $N=5$ \\
\hline Transformers turns ratio & $n=5$ \\
\hline Number of SMs in Arm1 and Arm2 & $m_{1}=m_{2}=9$ \\
\hline Max. duty ratio of VBMs & $D_{\max }=0.8$ \\
\hline Ripple factors & $x=10 \%, y=2 \%$ and $z=10 \%$ \\
\hline VBMs capacitances & $C_{c l}=80 \mu \mathrm{F}$ and $C_{c 2}=10 \mu \mathrm{F}$ \\
\hline VBMs inductances & $L_{i n}=2 \mathrm{mH}$ \\
\hline MMC-SM capacitances & $C_{A 1}=C_{A 2}=2 \mu \mathrm{F}$ \\
\hline
\end{tabular}

TABLE I

SUPG PARAMETERS SELECTION TO GENERATE 10KV PULSES
Because the energy transfer is conducted through the boosting modules capacitors $C_{c 1}$ and $C_{c 2}$, the SMs capacitance values of Arm1 and Arm2 can be relatively small. The upper switches in SM cells $\left(S_{A l j x}\right.$ and $\left.S_{A 2 k x}\right)$ are responsible for discharging the capacitors when their terminal voltages increase above the desired range for any unexpected reason in order to ensure balanced voltages across the cells. Based on the previous analysis, the parameters of the proposed system are as in Table I for generating a HV pulses of $10 \mathrm{kV}$ peak. For modular design, all the transformers are wound for isolation and clearance voltage higher than the peak value of the pulses as this stress voltage is experienced by the cell at the highest potential. In addition, if the ground point is moved to the point $m$, the required insulation voltage will drop to half the output voltage, without affecting the main operation of the converter.

\section{Simulation Results}

MATLAB/SIMULINK simulations of the SUPG in Fig. 4, with the values in Table I, illustrate the operation of the proposed HV topology.

TABLE II

SUPG PARAMETERS FOR THE EXPERIMENTAL RIG

\begin{tabular}{|c|c|}
\hline Parameter & Value \\
\hline Input dc voltage & $V_{i n}=50 \mathrm{~V}$ \\
\hline Output Pulse peak-voltage & $V_{p}=500 \mathrm{~V}$ \\
\hline Load resistance & $R=100 \Omega$ \\
\hline Switching time & $t_{s}=100 \mu \mathrm{s}$ \\
\hline Number of VBMs & $N=2$ \\
\hline Transformers turns ratio & $n=1$ \\
\hline Number of SMs in Arm1 and Arm2 & $m_{l}=m_{2}=2$ \\
\hline Maximum duty ratio of VBMs & $D_{\max }=0.8$ \\
\hline VBMs capacitances & $C_{c l}=10 \mu \mathrm{F}$ and $C_{c 2}=10 \mu \mathrm{F}$ \\
\hline VBMs inductances & $L_{i n}=30 \mathrm{mH}$ \\
\hline MMC-SM capacitances & $C_{A l}=C_{A 2}=2 \mu \mathrm{F}$ \\
\hline IGBT switches part no. & $\mathrm{FGY} 75 \mathrm{~N} 60 \mathrm{SMD}$ \\
\hline
\end{tabular}

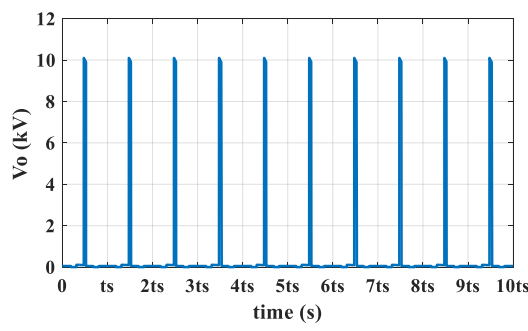

(a)

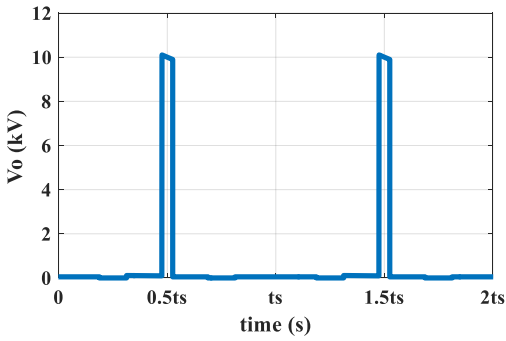

(b)

Fig. 5. Simulation results of Load voltage pulses with $10 \mathrm{kHz}$ repetition rate and pulse duration of $5 \mu \mathrm{s}$. (a) Train of pulses. (b) Zoomed-view of the pulses train. 


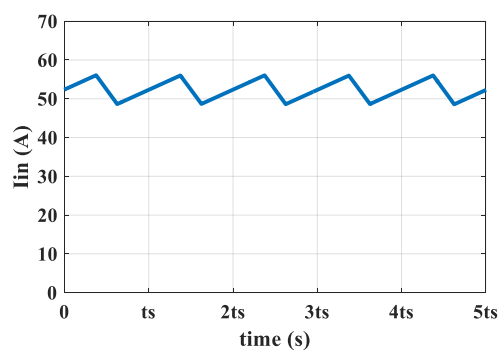

(a)

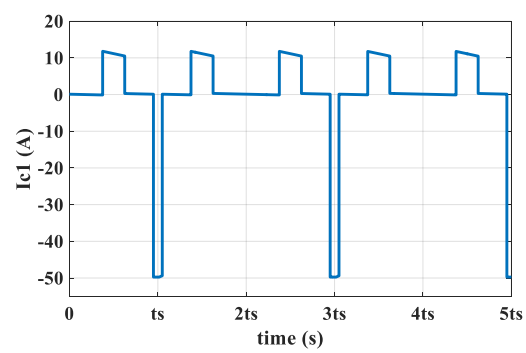

(d)

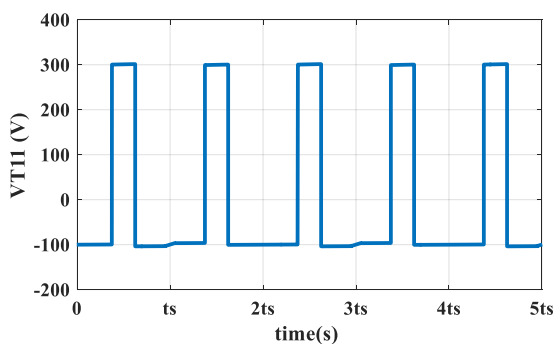

(g)

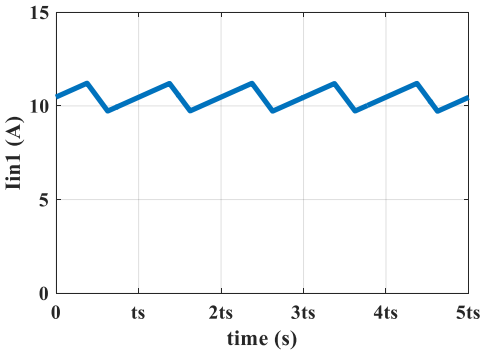

(b)

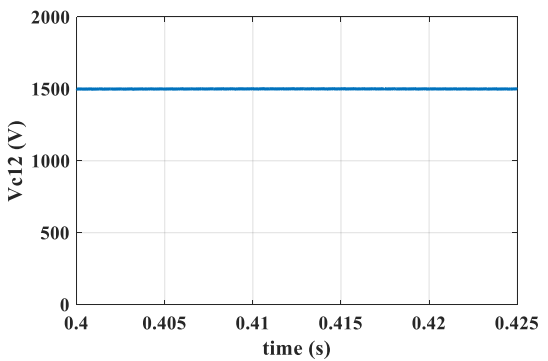

(e)

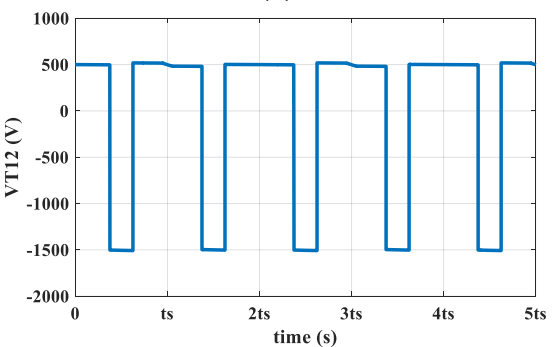

(h)

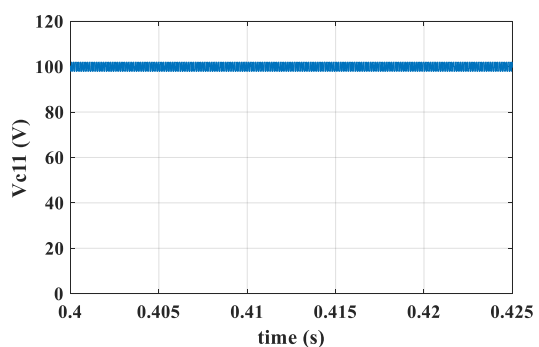

(c)

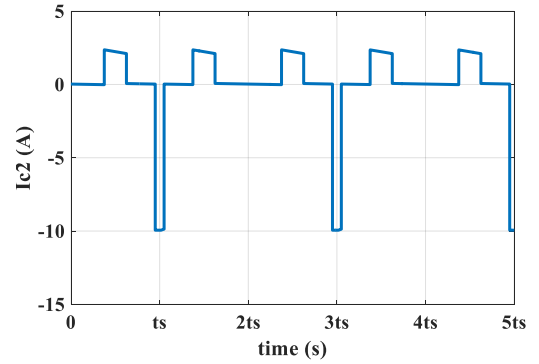

(f)

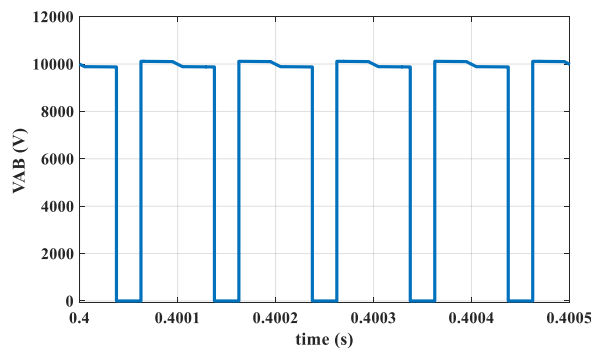

(i)

Fig. 6. Simulations of current and voltage waveforms at different parts of the SUPG (5kHz repetition rate and pulse duration of 20 $\mu$ s). (a) Total input current drawn from the dc-input supply. (b) First VBM input current. (c) First VBM primary side capacitor voltage ( $\left.V_{c 11}\right)$. (d) First VBM primary side capacitor current. (e) First VBM secondary side capacitor voltage $\left(V_{c 12}\right)$ (f) First VBM secondary side capacitor current (g) Voltage across the first VBM primary side $\left(V_{T I 1}\right)$. (h) Voltage across the first VBM secondary side $\left(V_{T I 2}\right)$. (i) Total terminal voltage $\left(V_{A B}\right)$

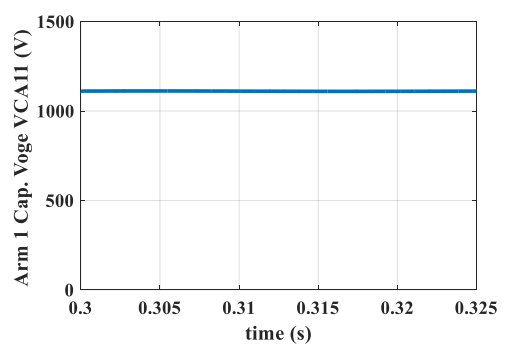

(a)

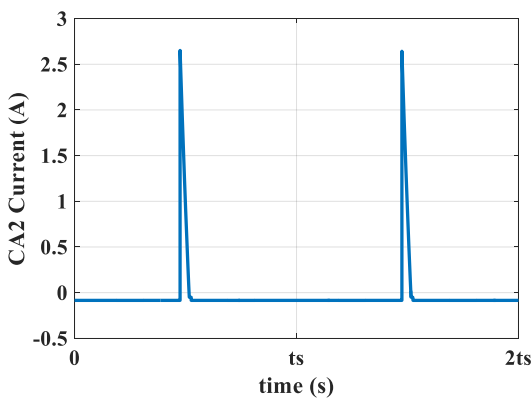

(d)

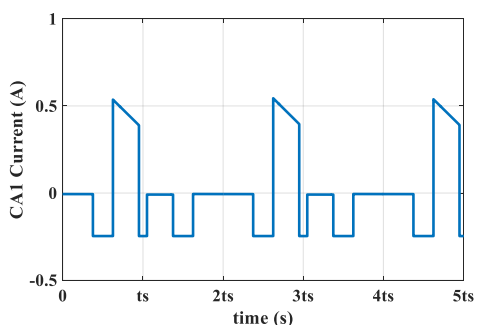

(b)

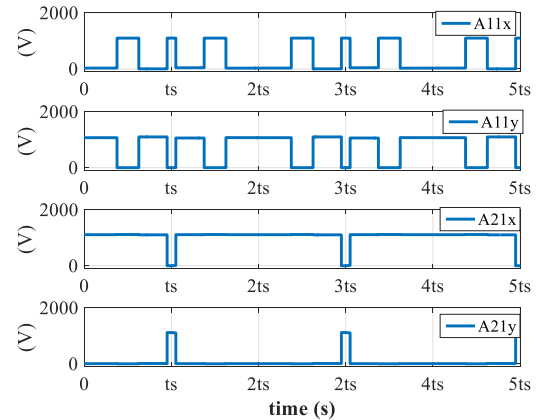

(e)

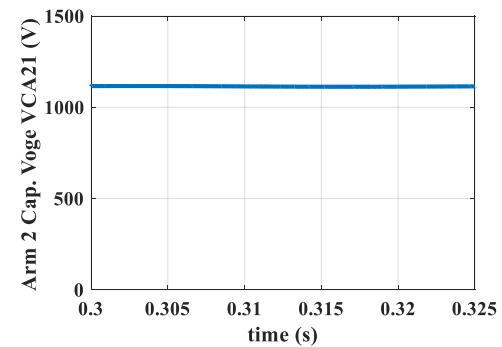

(c)

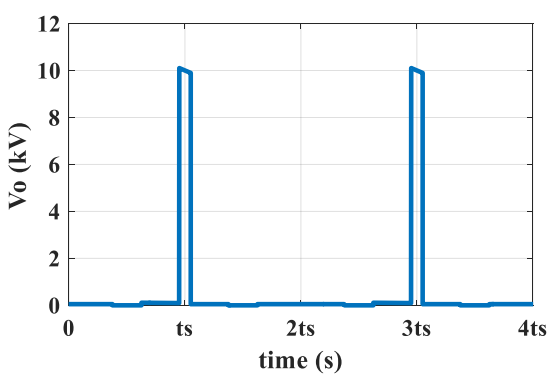

(f)

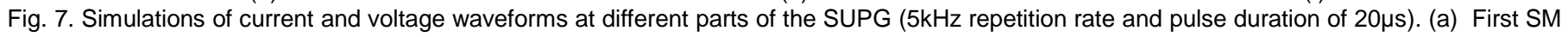
capacitor voltage in Arm1. (b) First SM capacitor current in Arm1. (c) First SM capacitor voltage in Arm2. (d) First SM capacitor current in Arm2. (e) Switches voltages, and (f) Output pulses with $5 \mathrm{kHz}$ repetition rate and pulse duration of $20 \mu \mathrm{s}$. 


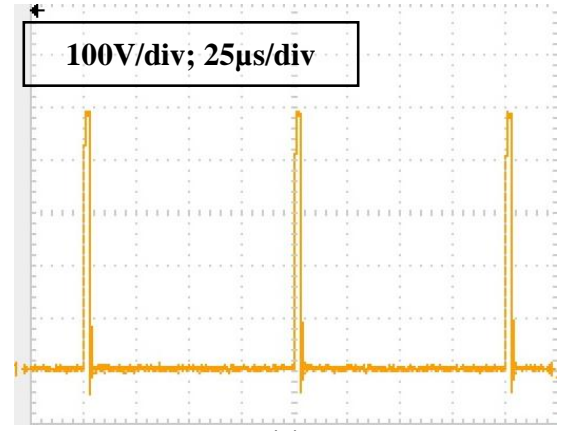

(a)

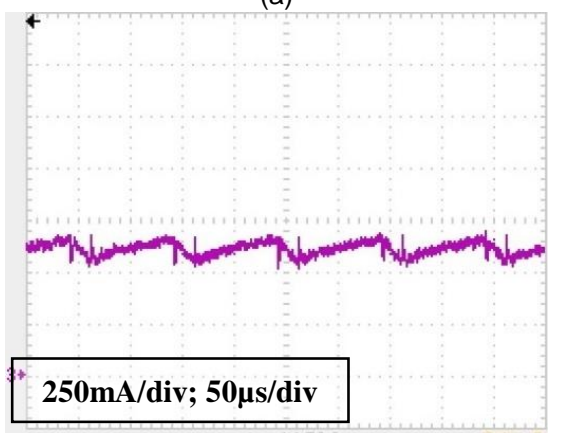

(d)

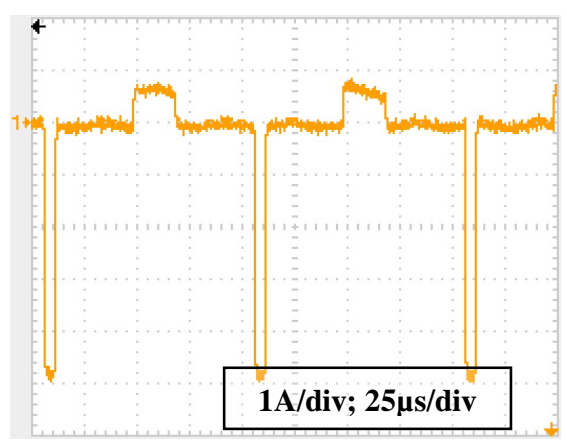

(g)

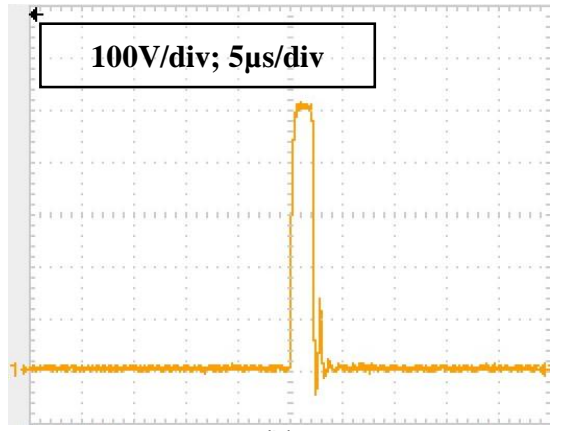

(b)

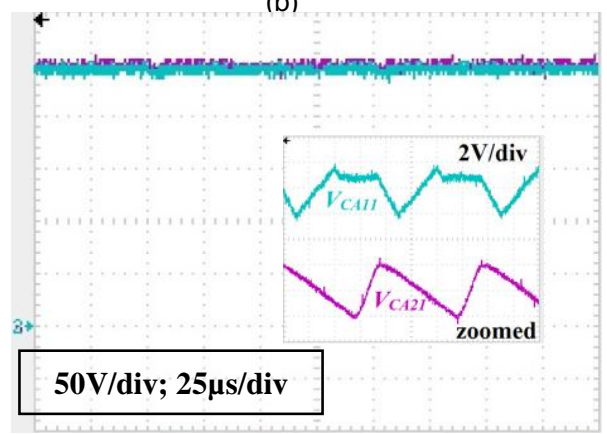

(e)

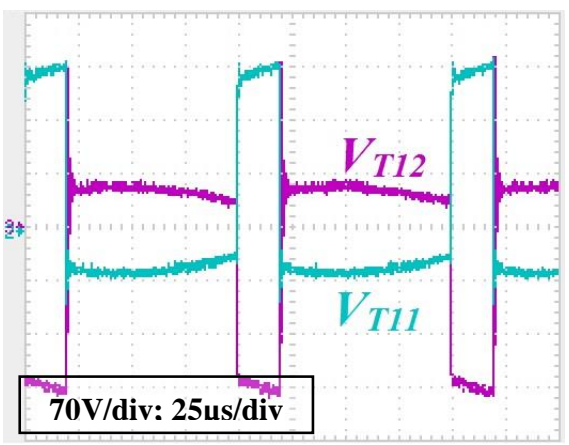

(h)

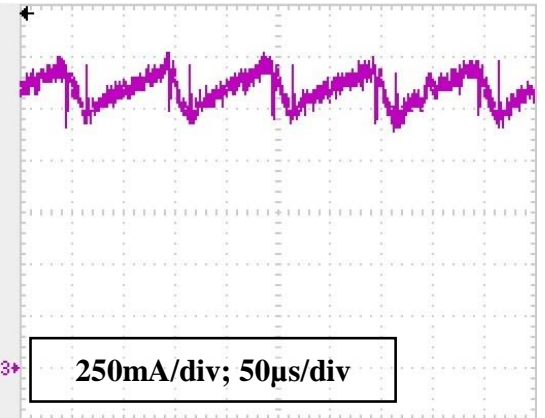

(c)

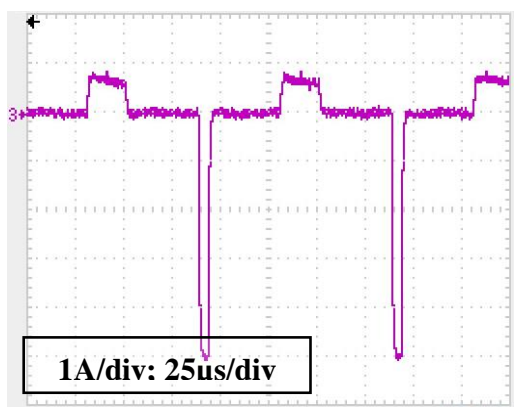

(f)

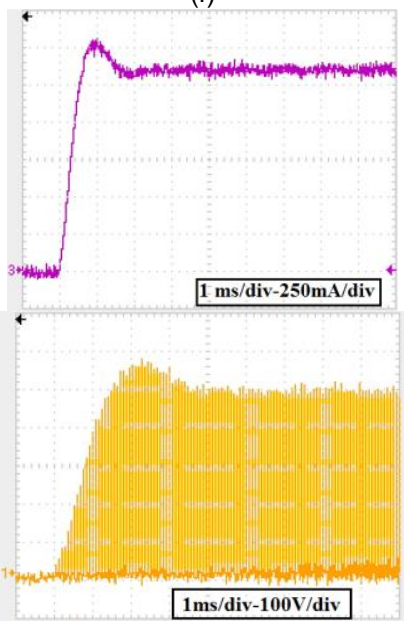

(i)

Fig. 8. Experimental results of the scaled-down SUPG topology. (a) Output pulses train of with $10 \mathrm{kHz}$ repetition rate and pulse duration of $2.5 \mu \mathrm{s}$. (b) Zoomed-view for a single pulse. (c)Total input current drawn from the dc-input supply. (d) First VBM input current. (e) SM-Capacitors voltage in Arm1 and Arm2 (Ch2: $V_{C A 11}$ and Ch3: $V_{C A 21}$ ). (f) Current through Cc1. (g) Current through Cc2. (h) Voltage across the first VBM primary and secondary sides. (i) Input current and output voltage dynamic response during starting.

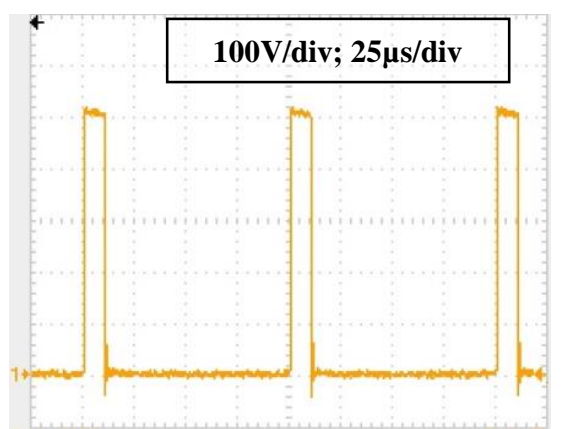

(a)

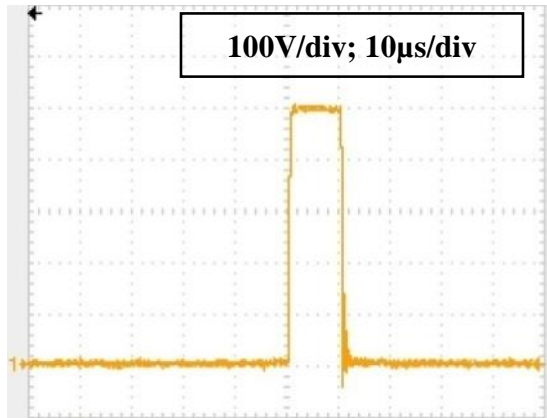

(b)

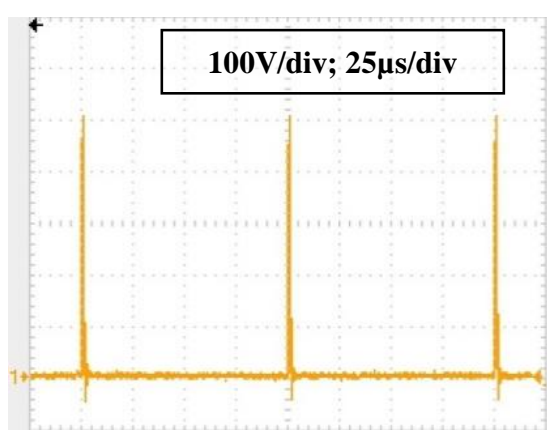

(c) 


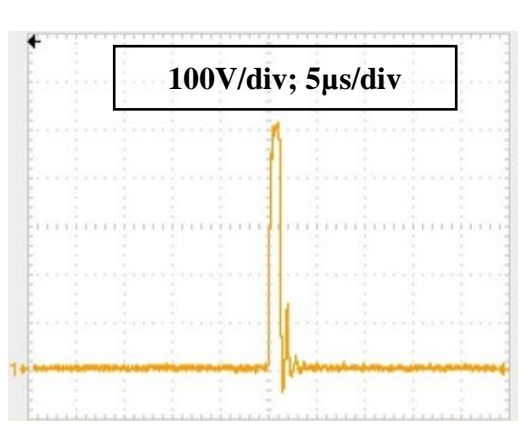

(d)

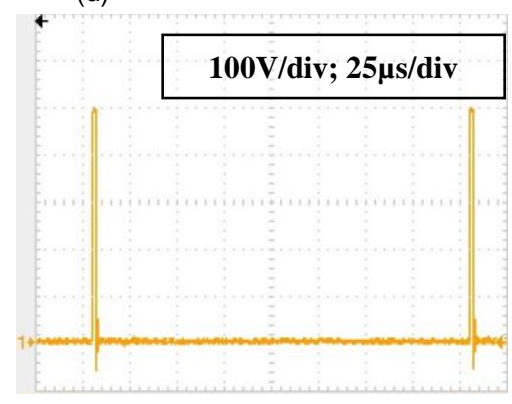

(g)

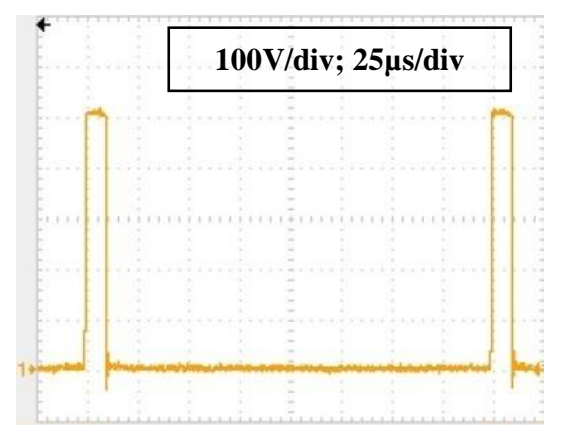

(e)

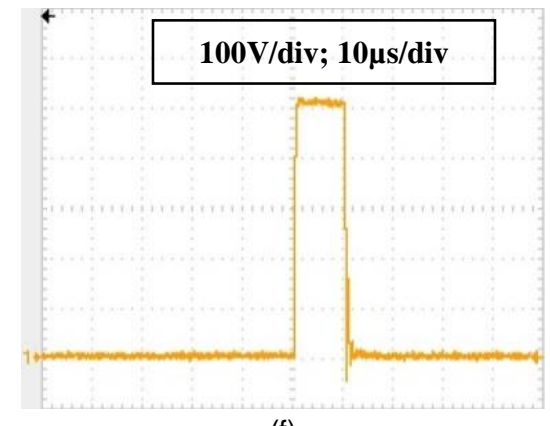

(f)

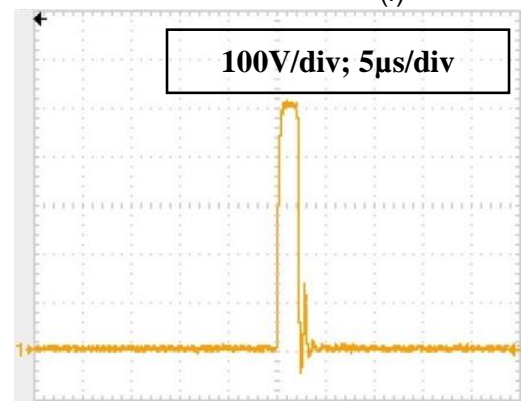

(h)

Fig. 9. Experimental results of generating different pulse repetition-rates and pulse-durations by the scaled-down SUPG topology. (a) Train of 10 $\mathrm{kHz}$ and $10 \mu$ s pulses. (b) Zoomed view of (a). (c) Train of $10 \mathrm{kHz}$ and $2.5 \mu$ s pulses. (d) Zoomed view of (c). (e) Train of $5 \mathrm{kHz}$ and $10 \mu \mathrm{s}$ pulses. (f) Zoomed view of (e). (g) Train of $5 \mathrm{kHz}$ and $2.5 \mu \mathrm{s}$ pulses. (h) Zoomed view of $(\mathrm{g})$.

Fig. 5 shows the load voltage pulses with $\delta=0.05$ (that is the generated pulse time is $5 \mu \mathrm{s}$ ) and when the repetition rate of the output train pulses is equal to the switching frequency of the boosting modules $\left(f_{s}=10 \mathrm{kHz}\right)$. Nevertheless, the generated pulses repetition rate is independent of $f_{s}$ and can be varied according to the application.

The key performance current and voltage waveforms at different parts of the SUPG are depicted in Fig. 6. Fig. 6a shows the total input current drawn from the input supply, while the first VBM current is shown in Fig. $6 \mathrm{~b}$ with one-fifth the total input current as expected. The capacitor voltages of the primary, $V_{c l l}$, and secondary, $V_{c l 2}$, sides of the first VBM are shown in Figs. 6c and 6e, respectively. The currents through $C_{c 1}$ and $C_{c 2}$ are shown in Fig. 6d and 6f. The terminal voltage $V_{A B}$ is shown in Fig. $6 \mathrm{i}$.

The voltages across the primary $\left(V_{T 11}\right)$ and secondary $\left(V_{T 12}\right)$ of the first VBM are shown in Figs. $6 \mathrm{~g}$ and $6 \mathrm{~h}$, respectively, which confirm the voltage second balance for the transformer. The individual SM voltages in Arm1 and Arm2 are explored in Figs. 7a and 7c, respectively. As aforementioned, the generated output pulse train repetition rate not necessarily the same as the VBMs switching frequency. Therefore, Fig. $7 \mathrm{f}$ shows the output voltage pulses with repetition rate of $5 \mathrm{kHz}$ and pulse duration of $20 \mu \mathrm{s}$ when the boosting modules switching frequency is $f_{s}=10 \mathrm{kHz}$.

During the starting of the proposed converter, the duty ratio $D$ can be increased gradually following a first-order capacitive circuit manner until it reaches the final steady-state value in order to ease the charging process of the SM capacitors and avoid exceeding the acceptable limits.

\section{EXPERIMENTAL RESULtS}

To show operation of the proposed system and validate the mathematical analyses and simulation results, a scaled-down hardware prototype with the parameters in Table II and controlled with Texas Instruments TMS320F28335 DSP is constructed. Fig. 8a shows a train of the experimentally generated output voltage pulses with $500 \mathrm{~V}$ pulse-peak, $10 \mathrm{kHz}$ repetition rate and $2.5 \mu$ s pulse duration. A zoomed view for a single pulse is depicted in Fig. 8b. Figs. 8c and 8d show the total input current drawn from the input supply and the first VBM drawn current, it is clear that since two VBMs are utilized, the first VBM draw one-half the total input current. The first SM-capacitor voltage in Arm1 and Arm2 are explored in Fig. 8e. The current through the first SMcapacitors $\left(C_{c 1}\right.$ and $\left.C_{c 2}\right)$ are shown in Figs. $8 \mathrm{f}$ and $8 \mathrm{~g}$, respectively. Moreover, the voltages across the primary $\left(V_{T 11}\right)$ and secondary $\left(V_{T 12}\right)$ of the first VBM are shown in Fig. 8h. To show the dynamic performance of the proposed pulse generator, Fig. 8i shows the input current drawn from the LVDC supply as well as the created output voltage pulses across the load from the starting moment.

Finally, the flexibility of generating wide range of different pulse repetition rates and pulse durations are explored in Fig. 9. With pulse duration of $10 \mu \mathrm{s}$ and repetition rate of $10 \mathrm{kHz}$, Fig. 9a shows the generated train of pulses with zoomed-view for individual pulse at Fig. 9b. Additionally, Figs. 9c and 9d explore the train of pulses with the same $10 \mathrm{kHz}$ repetition rate and $2.5 \mu$ s pulse durations. Figs. $9 \mathrm{e}$ and $9 \mathrm{f}$ show pulses with 5 $\mathrm{kHz}$ repetition rate and $10 \mu \mathrm{s}$ pulse duration, while Figs. $9 \mathrm{~g}$ and $9 \mathrm{~h}$ show pulses with $5 \mathrm{kHz}$ repetition rate and $2.5 \mu$ s pulse duration. The experimental prototype is shown in Fig. 10. 


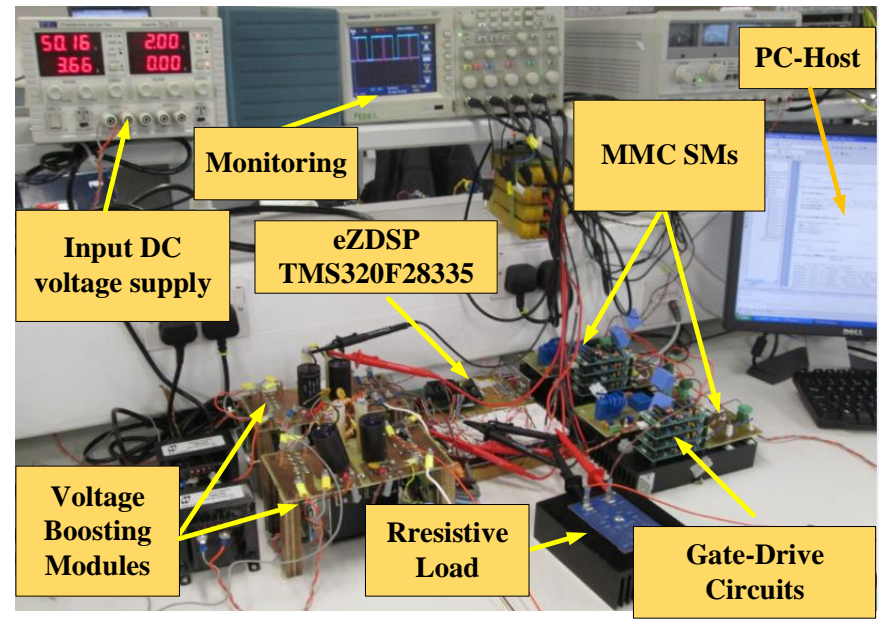

Fig. 10. The scaled-down experimental set-up.

\section{CONCLUSION}

This paper proposed a new HV pulse generator topology for electroporation applications. The topology employs inputparallel/output-series boosting modules in order to permit the use of a low voltage dc input supply. The amplified HV voltage is chopped with two MMC arms incorporating small clamping capacitors. Unlike many step-up HV generators in the literature, the boosting module capacitors of the proposed topology are charged simultaneously, allowing operation with a wide range of pulse widths and repetition rates. The simultaneous charging and discharging of VBMs implies that their switch gate signals are common to controller, consequently the control burden is low. The carried out simulation results showed the operation of the proposed topology, where the input LVDC is amplified by one hundred times using only five VBMs. Scaled-down experiment confirmed the feasibility of the proposed topology when the LVDC input is amplified by ten times using only two VBMs. Despite the obtained high amplification gains, the stresses on the utilised components are equal and acceptable. Thus, the proposed modular configuration allows the use of the marketavailable voltage and current ratings semiconductors. Moreover, the proposed topology can be extended to generate bipolar voltage pulses, which may be required for some irreversible electroporation applications, with two additional MMC arms across the treatment chamber.

Finally, the main contribution of the proposed SUPG topology can be summarized as:

- It achieves an HV pulse voltage by employing a three-folded stepping-up technique (VBMs duty ratio, step-up transformers turns ratio and series connection of the VBMs) from the LVDC input supply.

- It avoids using HV switches and series connection of switches to chop the generated HVDC voltage.

- It has the ability of generating unipolar/bipolar rectangular pulses with flexible voltage peak, repetition rate and pulse duration.

- It does not require voltage sensors.
- Its MMC SM capacitors, of small capacitance, are charged swiftly and simultaneously.

- It provide redundancy, modularity and scalability by employing several identical VBMs and MMC SMs.

- It allows the use of market-available components.

\section{REFERENCES}

[1] S. H. Jayaram, "Sterilization of liquid foods by pulsed electric fields," IEEE Electr. Insul. Mag., vol. 16, no. 6, pp. 17-25, 2000.

[2] M. Rezanejad, A. Sheikholeslami, and J. Adabi, "Modular switched capacitor voltage multiplier topology for pulsed power supply," IEEE Trans. Dielect. Elect. Insulation, vol. 21, no. 2, pp. 635-643, Apr. 2014.

[3] A. Abou-Ghazala, S. Katsuki, K. H. Schoenbach, F. C. Dobbs, and K. R. Moreira, "Bacterial decontamination of water by means of pulsed-corona discharges," IEEE Trans. Plasma Sci., vol. 30, no. 4, pp. 1449-1453, 2002.

[4] H. Sarnago, O. Lucia, A. Naval, J. M. Burdio, Q. Castellvi, and A. Ivorra, "A versatile multilevel converter platform for cancer treatment using irreversible electroporation," IEEE Journal of Emerging and Selected Topics in Power Electronics, vol. 4, no. 1, pp. 236-242, 2016.

[5] M. A. Elgenedy, A. Darwish, S. Ahmed, and B. W. Williams, "A transition arm modular multilevel universal pulse-waveform generator for electroporation applications," IEEE Trans. Power Electron., vol. PP, no. 99, pp. 1-1, 2017.

[6] M. Rebersek and D. Miklavcic, "Advantages and disadvantages of different concepts of electroporation pulse generation," Automatika-Journal for Control, Measurement, Electronics, Computing and Communications, vol. 52, no. 1, pp. 12-19, 2011.

[7] L. M. Redondo, "A dc voltage-multiplier circuit working as a highvoltage pulse generator," IEEE Trans. Plasma Sci., vol. 38, no. 10, pp. 2725-2729, 2010.

[8] L. Lamy Rocha, J. F. Silva, and L. M. Redondo, "Multilevel highvoltage pulse generation based on a new modular solid-state switch," IEEE Trans. Plasma Sci., vol. 42, no. 10, pp. 2956-2961, Oct. 2014.

[9] A. A. Elserougi, A. M. Massoud, and S. Ahmed, "Modular multilevel converter-based bipolar high-voltage pulse generator with sensorless capacitor voltage balancing technique," IEEE Trans. Plasma Sci., vol. 44, no. 7, pp. 1187-1194, 2016.

[10] M. A. Elgenedy, A. Darwish, S. Ahmed, and B. W. Williams, "A modular multilevel generic pulse-waveform generator for pulsed electric field applications," IEEE Trans. Plasma Sci., vol. 45, no. 9, pp. 2527-2535, 2017.

[11] I. Abdelsalam, M. A. Elgenedy, S. Ahmed, and B. W. Williams, "Full-bridge modular multilevel submodule-based high-voltage bipolar pulse generator with low-voltage dc, input for pulsed electric field applications," IEEE Trans. Plasma Sci., vol. PP, no. 99, pp. 1-8, 2017.

[12] M. A. Elgenedy, A. Darwish, S. Ahmed, and B. W. Williams, "A modular multilevel-based high-voltage pulse generator for water disinfection applications," IEEE Trans. Plasma Sci., vol. 44, no. 11, pp. 2893-2900, 2016.

[13] A. Elserougi, A. M. Massoud, and S. Ahmed, "A modular highvoltage pulse-generator with sequential charging for water treatment applications," IEEE Trans. Ind. Electron., vol. 63, no. 12, pp. 7898-7907, 2016.

[14] M. A. Elgenedy, A. M. Massoud, S. Ahmed, and B. W. Williams, "A high-gain, high-voltage pulse generator using sequentiallycharged modular multilevel converter sub-modules, for water disinfection applications," IEEE Journal of Emerging and Selected Topics in Power Electronics, vol. PP, no. 99, pp. 1-1, 2017.

[15] H. Shi, Y. Lu, T. Gu, J. Qiu, and K. Liu, "High-voltage pulse waveform modulator based on solid-state marx generator," IEEE Trans. Dielectr. Electr. Insul., vol. 22, no. 4, pp. 1983-1990, 2015.

[16] A. Elserougi, A. M. Massoud, A. M. Ibrahim, and S. Ahmed, "A high voltage pulse-generator based on dc-to-dc converters and 
capacitor-diode voltage multipliers for water treatment applications," IEEE Trans. Dielectr. Electr. Insul.,vol. 22, no. 6, pp. 3290-3298, 2015.

[17] L. M. Redondo and J. F. Silva, "Flyback versus forward switching power supply topologies for unipolar pulsed-power applications," IEEE Trans. Plasma Sci., vol. 37, no. 1, pp. 171-178, Jan. 2009.

[18] A. Elserougi, A. M. Massoud, and S. Ahmed, "A boost-inverterbased bipolar high-voltage pulse generator," IEEE Trans. Power Electron., vol. 32, no. 4, pp. 2846-2855, 2017.

[19] B. W. Williams, Power Electronics: Devices, Drivers, Applications, and Passive Components. London, U.K.: Macmillan, 1992.

[20] M. A. Elgenedy, A. M. Massoud, D. Holliday, S. Ahmed and B. Williams, "Low-voltage DC input, high-voltage pulse generator using nano-crystalline transformer and sequentially charged $\mathrm{mmc}$ sub-modules, for water treatment applications" in Proc. IEEE Energy Conversion Congress and Exposition (ECCE), Cincinnati, Ohio, 2017, pp.2144-2149.

[21] X. Zhang and T. C. Green, "The modular multilevel converter for high step-up ratio dc-dc conversion," IEEE Trans. Ind. Electron., vol. 62, no. 8, pp. 4925-4936, 2015.

[22] A. Darwish, A. M. Massoud, D. Holliday, S. Ahmed and B. W. Williams, "Single-Stage Three-Phase Differential-Mode BuckBoost Inverters With Continuous Input Current for PV Applications," in IEEE Transactions on Power Electronics, vol. 31, no. 12, pp. 8218-8236, Dec. 2016.

[23] A. Darwish et al., "A single-stage three-phase DC/AC inverter based on Cuk converter for PV application," in Proc. 7th IEEE GCC Conf. Exhibit., Nov. 2013, pp. 384-389.

[24] A. D. Badawy, " Current source dc-dc and dc-ac converters with continuous energy flow," Degree of Doctor of Philosophy, Department of Electronics and Electrical Engineering, University of Strathclyde, Glasgow, 2015.

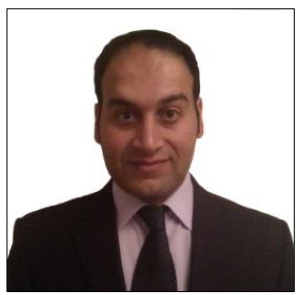

Ahmed Darwish received the B.Sc. and M.Sc. degrees in electrical engineering from the Faculty of Engineering, Alexandria University, Egypt, in 2008 and 2012, respectively, and the Ph.D degree in electric engineering from Electric and Electronic Engineering Department at the University of Strathclyde, Glasgow, U.K., in 2015.

From 2009 to 2012, he was a Research Assistant at Texas A\&M University at Qatar. From 2015, he was a Postdoctoral Research Associate with PEDEC group at the University of Strathclyde for two years. He has joined Lancaster University as a Lecturer in Electrical Engieering in 2017. His research interests include dc-dc converters, multi-level converters, electric machines, digital control of power electronic systems, energy conversion, renewable energy, and power quality.

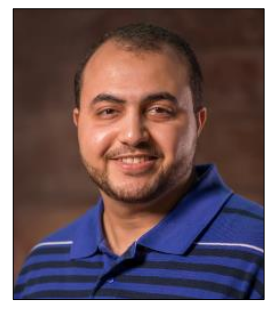

Mohamed A. Elgenedy (S'15) received the B.Sc. (with first-class honors) and M.Sc. degrees in Electrical Engineering from Alexandria University, Egypt in 2007 and 2010 respectively. Currently he is working toward the Ph.D. degree at the University of Strathclyde, Glasgow, U.K. He is also an assistant lecturer with the Electrical Engineering Department, Faculty of Engineering, Alexandria University. In 2012, he was with Spiretronic LLC, Houston, TX, USA, as a Research Engineer. From 2013 to 2014, he was a Research Associate at Texas A\&M University at Qatar, Doha, Qatar. His research interests include high power electronics, pulse power generator, electric machine drives, energy conversion, and renewable energy.

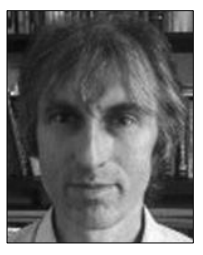

Stephen J. Finney received the M.Eng. degree from the Loughborough University of Technology, Loughborough, U.K., in 1988, and the Ph.D. degree from Heriot-Watt University, Edinburgh, U.K., in 1995, both in electrical engineering. For two years, he was at the Electricity Council Research Centre Laboratories, Chester, U.K. For twelve years, he was a Professor with the University of Strathclyde, Glasgow, U.K. He is currently a Chair in Power Electronics, Electronics and Electrical Engineering department at the University of Edinburgh, Edinburgh, U.K. His research interests include high-voltage directcurrent, modular multilevel converter, renewable generation, and electrical vehicle.

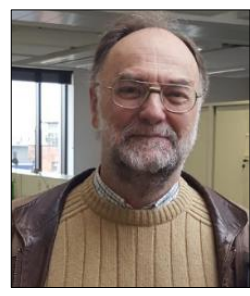

Barry W. Williams received the M.Eng.Sc. degree from the University of Adelaide, Australia, in 1978, and the Ph.D. degree from Cambridge University, Cambridge, U.K., in 1980. After seven years as a Lecturer at Imperial College, University of London, U.K., he was appointed to a Chair of Electrical Engineering at Heriot-Watt University, Edinburgh, U.K, in 1986. He is currently a Professor at Strathclyde University, UK. His teaching covers power electronics (in which he has a free internet text) and drive systems. His research activities include power semiconductor modelling and protection, converter topologies, soft switching techniques, and application of ASICs and microprocessors to industrial electronics.

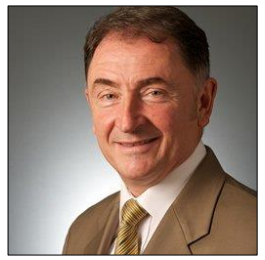

Jim R. McDonald (M'90) received the B.Sc., M.Sc., and Ph.D. degrees from the University of Strathclyde, Glasgow, U.K. He was appointed as the Rolls-Royce Chair in Electrical Power Engineering in 1994 and became Head of Department in 2003 at the University of Strathclyde. He has been Director of the Institute for Energy and Environment at the University of Strathclyde and, in early 2009, was appointed Principal and Vice Chancellor of the University of Strathclyde. He is a member of the Power Academy Executive, the author of many technical papers, and co-author of two books 